\title{
Opportunities for emergency medicine training in Australia
}

\author{
John M Ryan, Paul L Gaudry
}

\begin{abstract}
Opportunities exist for graduates from the United Kingdom to undertake some of their emergency medicine training in Australia. Guidelines for graduates are presented on when to travel, how to find a position, what information one should obtain about a position, and how to acquire the necessary visa and medical registration. A successful visit takes some time to plan and requires cooperation between the negotiating parties. The graduate who undertakes training abroad can expect to benefit professionally and personally. The development of an international exchange network for trainees would streamline the process and broaden the appeal to graduates of completing some of their emergency medicine training in another country.

(F Accid Emerg Med 1997;14:36-39)
\end{abstract}

Keywords: postgraduate training; emergency medicine; Australia

Workforce is a global issue in emergency medicine. This creates opportunities for individuals to experience the benefits of travel, the sharing of ideas, and additional training by working in emergency medicine in another country. Exchange of staff between emergency departments in different countries will grow when these benefits become better known and appreciated by the international community involved in the provision of emergency care. This paper is concerned with advising trainees from the United Kingdom on how to gain training positions in Australia. It is based on the experience of one of the authors (JMR) but deals generically with the issues of obtaining a position, arranging the move, and obtaining the maximum professional benefit from the venture.

\section{When to travel}

Emergency departments in larger hospitals in Australia are in many cases staffed by four or five consultants, six to eight emergency medicine trainees who are typically in their third to seventh year postgraduation, and junior staff comprising interns and resident medical officers (RMOs). Trainees are designated as either senior RMOs or registrars, depending on local practices. Interns are the equivalent of house officers, and RMOs are the equivalent of senior house officers (SHOs) in the UK. It is important to note that the medical year nominally begins in January or February in Australia but some new staff are recruited mid-year to fill both planned and unplanned vacancies. The larger departments compete each year to recruit up to three new emergency medicine trainees to meet the workforce needs of the department and to honour its commitment to a training programme that includes several specialty rotations. There can be a mismatch of the domestic supply and demand for trainees, leading in recent years to a pattern of overseas recruitment, even by favoured departments.

Departments hoping to attract UK graduates will understandably have a preference for an experienced career registrar, but increasingly departments are seeking SHOs. First year SHOs may view this as the optimal time to travel before they start a career post of higher specialist training or general practice. One should be wary in case vacancies at this level are because of an inability to fill RMO posts locally due to poor conditions, lack of supervision, or unpopular locations.

Next in experience are the second or third year SHOs who are planning a career in emergency medicine. They may already have six to twelve months' experience in emergency medicine. In particular they may seek a six month post in emergency medicine and a six month rotation to another relevant post such as anaesthetics, intensive care, cardiology, orthopaedics, or paediatrics.

Then there are specialist registrars. They will need to seek leave of absence from their training rotation and will also need to seek confirmation from the Joint Committee on Higher Medical Training and the Specialist Advisory Committee for Accident and Emergency Medicine that the post is accredited for training. Currently it is unlikely that any trainee would be released for more than six 


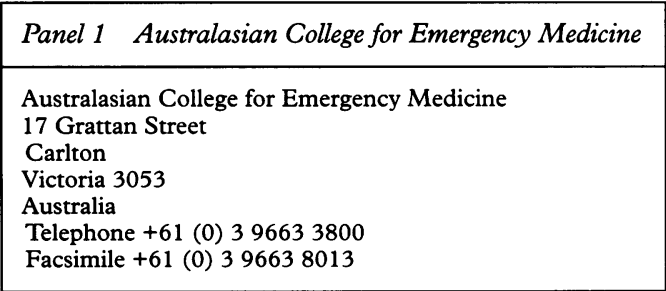

months. A good option for UK hospitals may be to develop an association with an Australian hospital and enter into an exchange programme for registrars. The final type of doctor who may be attracted by the opportunities in Australia is one who has completed accredited training but is keen to travel before taking up a consultant post. Such doctors will wish to improve their knowledge base of emergency medicine by experiencing a different healthcare system, borrowing new ideas, performing research in a new environment, and participating in the global network of emergency medicine.

\section{Finding a position}

Departments with an interest in recruiting UK graduates will normally advertise in the British Medical fournal. All overseas positions are advertised at the back of the classifieds supplement. Australian domestic advertisements are in the employment sections of the national newspaper (The Australian) and in the capital city newspapers. The Weekend Australian is much the best newspaper to buy in the UK. The classifieds sections of these newspapers can also be accessed on the Internet and some hospitals have a web site. UK graduates should plan a lead time of six months and preferably nine to twelve months between finding and taking up a position. The Australasian College for Emergency Medicine (ACEM) publishes a list of emergency departments in Australia and New Zealand accredited for emergency medicine training. This list also provides some details about the department and the name of the director of emergency medicine training, from whom more details can be obtained about the hospital and any positions vacant (panel 1). Contacting a colleague who has worked in Australia, ideally in an emergency department, is invaluable for candid comment about their experiences.

\section{Interpreting the advertisement}

International recruitment requires attention to the details and features of the advertisement. It should specify the number of emergency medicine consultants and registrars in the department. A description of the department's case mix and attendances by triage category, not simply the annual census, is essential. ${ }^{1}$ Any features of the hospital especially relevant to emergency medicine, such as the trauma and toxicology services, should be highlighted. The advertisement should confirm that the post is accredited by the ACEM and if accreditation for training in emergency medicine has been obtained from the Joint Committee on Higher Medical Training. Features of the hospital

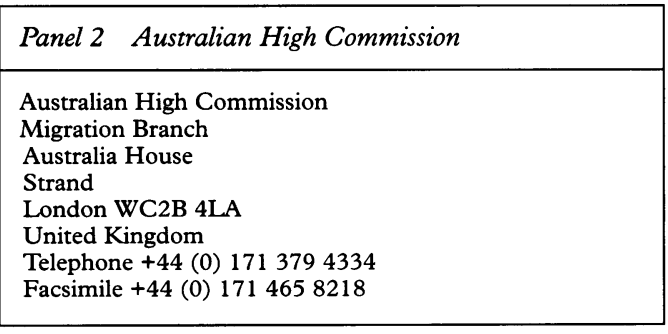

which should be included in the advertisement are university affiliation, role delineation, range of services available, catchment population, and bed numbers. The requirements for a work visa and for medical registration with the responsible Medical Board need to be mentioned, but details of these requirements plus the terms and conditions of employment and remuneration scales can be provided in response to specific inquiries. The advertisement should nominate a contact person, preferably the department's director, and include various communications options such as the department's mailing address, international telephone and facsimile numbers, and e-mail address.

\section{Information gathering}

Initial contact with the department in Australia should be by telephone. Interested candidates are then likely to be asked to send a facsimile of their curriculum vitae and nominate two professional referees. If a candidate is deemed suitable then a departmental and hospital information pack will usually be dispatched. Information should be sought on the department's didactic teaching programme, the ability to access in-house courses, scientific or continuing education meetings, and external courses. One such popular external course is the Early Management of Severe Trauma course, the equivalent of the Advanced Trauma Life Support course in the UK. It currently has an 18 month waiting list for provider courses but is worth inquiring about as late vacancies are filled from the waiting list. A list of the department's research publications should be provided. A formal offer of a position should include the terms and conditions of employment, remuneration scales (which should be in explicit terms, allowing for differences in grading terminology between the UK and Australia), and details of visa and registration procedures.

\section{Organising a visa}

An application for temporary residency and visa (usually a postgraduate training visa) must be made to the Australian High Commission in London (panel 2). This is potentially a protracted process and prerequisites are employment details from Australia and certification of the applicant's emergency medicine trainee status by the ACEM. Every effort should be made to ensure this documentation is available at the earliest possible date. Applicants will be required to undergo a medical examination and have a chest $x$ ray performed by doctors and radiologists nomi- 
nated by the High Commission. This will entail a fee of about $£ 150$. In addition there is a fee for the visa application. The duration of the contract should be defined or an extension of the visa may become necessary while in Australia, incurring further expense. Under a postgraduate training visa, work is restricted to the sponsoring employer and any locum work is prohibited. Furthermore a spouse will not be granted a work visa unless he or she is to be employed in a position that cannot be filled by an Australian citizen. This situation will need to be proven by the primary sponsoring employer before such a visa is granted to a spouse. The inability for a spouse to work is often the main reason that a position abroad is not accepted.

\section{Medical registration}

Approval for temporary registration with the state Medical Board in Australia is dependent on processing the visa application and details of obtaining registration may vary between states. This is unlike the situation in the UK where registration is controlled by the General Medical Council (GMC). It is essential to check with the relevant Medical Board as to what certified documentation will be required for registration. It may include evidence of completion of a preregistration year. A letter of good standing from the GMC takes some weeks to prepare and costs $£ 50$. Applicants need to give an undertaking in writing that they will return to the UK at the end of their contract and that they will not apply to take the examinations of the Australian Medical Council, a requirement for registration of overseas trained doctors seeking permanent residence in Australia.

\section{Taxation}

The doctor must inform HM Inspector of Taxes of intended departure and return a P45 form obtained when finishing employment in the UK. It is worth considering maintaining payments to the National Health Service Superannuation Scheme while abroad. Depending on the month of departure, this may lead to a substantial tax rebate. A doctor with children will not be eligible for children's allowances while in Australia. The doctor should also be aware of the differences between the UK and Australian tax systems. The Australian tax system has far greater allowances for work related and education expenses. Junior staff and trainees have to fund themselves for continuing education meetings and external courses, but work related expenses are tax deductible. If staying in Australia more than six months, election to be taxed as a resident is preferable when applying for a tax file number, as the tax penalties for non-resident status are quite severe. Australia and the UK have a reciprocal health agreement, but only emergency cover with the Australian Medicare system is available for holders of a postgraduate training visa. The doctor will also be charged the standard $1.5 \%$ Medicare levy despite being ineligible for a large range of healthcare services. Superannuation is de- ducted at a rate of $4 \%$ but can be reclaimed when the doctor finishes his term of employment.

\section{Arriving in Australia}

Early contact with the sponsoring hospital and its emergency department is recommended. The doctor will need to apply for a tax file number with the local Australian Tax Office and apply for a Medicare Card. These procedures should be facilitated by the hospital's medical administration. The doctor will need to present in person to the offices of the state Medical Board with certified copies of medical degrees, a letter from the GMC, and pay the Medical Board's fee before being registered to practice.

\section{Setting up home}

Furnished rented accommodation is difficult to obtain in many Australian cities. If the doctor can be provided with hospital accommodation this may be sufficient. However, for a family it is not easy to find a house and subsequently arrange for it to be adequately furnished. There may be a furnished flat or unit available which may suit a small family. Cars are more expensive than in the UK, but secondhand cars can be bought at any price. Insurance is somewhat cheaper for both cars and house contents. Having a valid no claims bonus certificate from a UK insurer may be helpful. A UK driver's licence or an international driver's licence obtainable from the Automobile Association is mandatory.

\section{Work practices}

Emergency medicine trainees working abroad in Canada, the UK, and the United States have reported favourably on their experiences. ${ }^{2-5}$ Collectively they describe the advantages of working in a new environment, within a different health care system. They have reviewed the differences that exist in staffing, training and work practices, research opportunities, subspecialisation, different approaches to nonmedical tasks, differences in case mix, and the approaches taken to many shared problems. What UK graduates can expect to achieve professionally by working in Australia will depend on their level of experience and the stage of their career. The case-mix, supervision, and staffing of the emergency department will determine the clinical experience and the degree of responsibility that can be expected. A minimum of six months in the emergency department in any 12 month post will be expected. If rotations to other specialties are expected, these should be negotiated before departure. The larger capital city hospitals are designated as major trauma hospitals, creating the opportunity - not always readily available in the UK - to experience how a major trauma system functions. The opportunity may exist for doctors interested in prehospital care to experience a paramedic system that provides a greater contribution in the field than in the UK. Furthermore the fixed wing and helicopter retrieval and transport services that cover 
the vast spaces of Australia present a new dimension in prehospital care to most UK doctors.

\section{Academia}

The ACEM holds an annual scientific meeting that is well worth attending. The scientific content is of the highest calibre and it is an opportunity to meet emergency medicine trainees and consultants from Australia and New Zealand. There is also a small contingent of registrants from countries in Asia and North America, as well as the UK. An annual winter meeting is held by the Australasian Society for Emergency Medicine (ASEM). Both meetings combine continuing education plenary sessions and free paper research sessions. The opportunity for research exists in most departments, and some non-clinical time for research may be negotiated at the time of application by more senior doctors. However, research is usually conducted in the doctor's own time. Most hospitals have well stocked libraries which take UK and North American journals of relevance to emergency medicine. Research has been encouraged by the ACEM by offering awards for both fellows and trainees at the annual scientific meetings. ${ }^{6}$ A component of training for fellowship of the ACEM is a requirement to present a paper at a recognised meeting or have a paper published in a refereed journal. The official journal of both the ACEM and the ASEM is Emergency Medicine (ISSN 10356851) and is published quarterly.

\section{Conclusion}

The process of organising a post in emergency medicine in Australia can be lengthy process and requires detailed planning and negotiation by both the doctor and the host hospital (table). Development of an international ex-

\section{Organising a position}

Deciding when to travel

Choosing a position

Obtaining a temporary work visa

Applying for medical registration

Living and working in Australia

change network would streamline this process and provide the doctor with a guarantee of a position on their return. Trainees and directors of training in the UK and Australia should be encouraged to both initiate and benefit from such a network.

The UK doctor can expect a warm, friendly, and supportive reception from his Australian colleagues. The Australian healthcare system is yet to experience the financial, budgetary, and managerial consequences of the National Health Service reforms of the UK. The work environment shares many of the problems experienced in the UK, such as access block and lack of sufficiently qualified medical and nursing staff, but the morale in emergency medicine in Australia is quite high. There is a feeling of optimism about the specialty which makes for a satisfying work time and an overall positive feeling from the experience of spending time in Australia.

The support and encouragement provided by $\mathrm{Mr} \mathrm{C} \mathrm{A}$ Perez-Avila of Brighton and Dr E Glucksman of King's College, to one of the authors (JMR) while he was organising his visit to Australia, is appreciated.

1 Australasian College for Emergency Medicine. ACEM Policy: National Triage Scale. Emerg Med 1994;6:145-6. 2 Ieraci S. An Australasian emergency physician in Vancouver. Emerg Med 1991;3:22- 6

3 Wilson P. A Fellowship year abroad: the 'pros' and 'cons'. Arch Emerg Med 1991;8:282-4.

4 Hitchcock T. Letter from Scotland. Emerg Med 1992;4: 24-5.

5 Brennan RJ. Reflections on an American emergency medicine fellowship. Emerg Med 1993;5:49-52.

6 Australasian College for Emergency Medicine. ACEM Regulations: qualification for election to Fellowship upon Examination. ACEM Training and Examination Handbook, 1996:7. 